\title{
Blockchain Challenges in Maritime Industry: An Empirical Investigation of the Willingness and the Main Drivers of Adoption by the Hellenic Shipping Industry
}

\author{
Georgios Kapnissis, Eleni-Ekaterini Leligou, Georgios Vaggelas \\ Department of Industrial Design and Production Engineering, University of West Attica, Athens, Greece \\ Email: mipapou@uniwa.gr
}

How to cite this paper: Kapnissis, G., Leligou, E.-E. and Vaggelas, G. (2020) Blockchain Challenges in Maritime Industry: An Empirical Investigation of the Willingness and the Main Drivers of Adoption by the Hellenic Shipping Industry. Open Journal of Applied Sciences, 10, 779-790.

https://doi.org/10.4236/ojapps.2020.1012055

Received: September 20, 2020

Accepted: December 8, 2020

Published: December 11, 2020

Copyright $\odot 2020$ by author(s) and Scientific Research Publishing Inc. This work is licensed under the Creative Commons Attribution International License (CC BY 4.0). http://creativecommons.org/licenses/by/4.0/

\begin{abstract}
In the shipping industry, significant part of the documents exchange still have the traditional paper form, mainly due to security concerns, despite the size and modernization efforts of this market. We explore the adoption of the blockchain and Distributed Ledger Technologies to address document exchange in a fast and secure way.
\end{abstract}

\section{Keywords}

Block Chain, Shipping Industry, Digitalization, Unmanned Vessels

\section{Introduction}

The digitalization of the shipping industry lags behind many other sectors of the economy despite the fact that it is responsible for the carriage of around $90 \%$ of world trade and is the backbone of world commerce [1]. Although many aspects of the shipping industry have been modernized and attempts to create unmanned vessels have attracted the research attention, the digitization (dematerialization) of the document exchange activity that accompanies the vessel and the load has not witnessed significant progress. Several attempts have been made since digitizing this process is expected to save large amounts of money and human and paper resources worldwide. For example, there are cases where the cargo arrives at the port and the relevant (paper) documents are not yet available at the destination port introducing high costs. The dematerialization attempts and their wide adoption has been hindered up to now primarily due to the reluctance of the involved actors to embrace them raising security concerns. They 
consider that keeping the documents in a server where multiple actors have access makes this server prone to attacks by adversaries. Additionally, mutual trust among the diverse actors cannot be assumed which triggers concerns about data integrity and modification.

The advent of blockchain technologies radically changes the landscape of secure data and document exchange affecting almost all sectors of the economy. While this technology has initially been proposed for financial exchanges (attempting to substitute the current banking system or run in parallel), it exhibits very important characteristics exploitable in many different cases. This technology mandates the storage of data in multiple devices across the world so that even if one of these "devices" is attacked, the data remain available. Another interesting characteristic is that once any piece of information is stored in the blockchain, no device/user can go back and alter it. Third (and not at all last), the participating entities establish trust among themselves since they need to be approved for this participation in order to ensure that all attempting malfunctioning will be traceable, identified and accused.

In this paper, we present processes of the maritime industry that would benefit from their dematerialization. Then, we proceed reviewing solutions that have been proposed to address the dematerialization processes and then turn our attention to blockchain-enabled solutions and the benefits they bring. We describe how Blockchain and Distributed Ledger Technologies can bridge the gap and help realize the transition from the paper to the digital form of Bill of Lading (BOL), which is one of the most important processes in the shipping industry. We also explore the use of different types of DLTs and present the few commercial solutions. Finally, we investigate how likely is for the blockchain technology to be adopted by the Hellenic shipping industry actors, and what are the main drivers of adoption.

Our goal and contribution is twofold: 1) to explain to maritime industry people and leaders why blockchain enabled solution is secure and reliable and can bring them all the benefits of a digitized process and 2) to guide shipping and IT companies with the results of the measurement of the willingness to adopt and use the blockchain for their future strategic planning.

\section{Stage One}

\subsection{Maritime Industry Processes}

The operation of the maritime industry entails the execution of multiple processes that ensure appropriate, timely and sale delivery of all kinds of goods around the world, through a complex and international ecosystem. In the sequel, we examine three processes that are currently performed through paper, are very bureaucratic, time consuming and thus inflate the transportation costs.

\subsection{Bill of Lading}

One of the most significant documents in international commercial transactions, 
which has been an integral component in the maritime shipping industry, is the bill of lading (BOL). It was the result of the inability to ensure that goods were delivered by the carrier to the correct consignee and also arrived at the consignee in the same quantity and quality as when delivered by the producer, consignor or exporter, to carrier.

Regardless of the types of BOL, as a document, in order to be considered valid, it must serve three basic functions, necessary for the separation of legal obligations and commitments between the parties:

1) It must be a conclusive receipt, i.e. an acknowledgement that the goods have been loaded

2) It must contain or evidence the terms of the contract of carriage, and

3) It must serve as a document of title to the goods, subject to the "nemo dat quod non habet" rule (literally meaning "no one gives what they don't have").

In addition to the above, various types of BOL have some additional features that allow them to be transferred as a transferable document of title, to another person while transferring the right to acquire and receive the goods they represent.

In this paper, we will focus and analyze the Negotiable BOL, because it is the most known obstacle of BOL transformation (form paper to paperless) and, unfortunately, the most complex subcategory.

A negotiable bill of lading (N/BOL) is distinguished by the fact that it is a contract of carriage that can be transferred to a third party. Under that definition, and in conjunction with its functions, a negotiable bill of lading (N/BOL):

1) Operates as a receipt providing evidence that goods conforming to the contract have been shipped as agreed and are in the physical possession of the carrier for delivery to the consignee at destination.

2) Contains or evidences the relevant terms of contract with the carrier.

3) Operates as a transferable document of title, and it is exactly this aspect, which makes it different to the non-negotiable bill of ladings.

While necessary for ensuring trust in international transactions, BOL significantly burdens the exchanges: Each BOL is often sent at least three times through a courier process, costing $\$ 100$ on average. With more than 50 million BOLs being created every year, the estimated total yearly cost of this process is approximately $\$ 5$ billion. Keeping $\mathrm{BOL}$ in paper format requires manual processing, increases the probability of being lost or forged. In maritime logistics, the shipper must mail physical copies of the bill to the importer of the goods. If the goods reach the importer in advance of BOL, the importer will not have the requisite document of title to present to the carrier. Not only will the carrier not accrue liability-neither in trover nor under statute-for withholding the goods, but the carrier may also have to place the goods in storage. This can result in demurrage costs as well as potentially causing other economic loss due to fluctuations in market value of the goods or an inability of the importer to meet obligations under other contracts [2]. It is evident that in this process mul- 
tiple actors are involved including carrier, consignees and others.

The above reasons, along with the advent of the internet, the development and spreading of electronic information systems, have largely led to the development of electronic solutions for the processing and transaction of BOLs also known as EDI (Electronic Data Interchange). The most significant examples approved by Clubs are Bolero, essDOCS, e-title, and edoxOnline.

A number of problems have emerged from this effort and as a result, we had a limited acceptance and adoption with an inability to replace the pre-existing situation with the new one. The most important of these [3] are presented below and are based both on systems analysis and research among users (carriers, consignors and consignees):

1) Commodity traders did not like to have their transactions recorded in a central registry.

2) The ultimate buyers of commodities did not want to acquire bills of lading from a registry actually supporting and servicing intermediaries and speculators.

3) The liability of e-Bill of Lading platforms was not established. This resulted in relatively expensive insurance contracts for the registry operations.

4) If the goods are to be sold to a party not being member of the specific e-Bill of Lading platform, the e-Bill of Lading may not be used anymore. In such a case the parties may have to switch to a paper bill of lading to be issued at that moment by the carrier on the request of the actual consignee.

5) All Contracting Parties must be members of this e-Bill of Lading platform and have signed and accepted the terms and conditions of this platform.

6) The platforms leave it on the responsibility of its users to assess if they comply with the laws of the country the user wishes to trade in or with. As the solutions are based on contractual relationships, legal uncertainty remains as to the acceptance and enforceability of the system in various jurisdictions.

7) In most cases, the platforms required the trade transaction to be financed by a letter of credit.

8) Not all banks (which are a key factor in the equation of transactions) accept an e-BOL as a warrant to credit or withdraw money from an account.

9) Lack of international legal framework.

10) There must always be a trusted third party.

Beyond the literature review, which concludes to the above factors, the United Nations Conference on Trade and Development researched the involved parties, to identify from the practical point of view, the obstacles using electronic platforms, and conclude that the top four obstacles are: Infrastructure/market/trading partners not yet ready; legal framework is not clear enough or is not adequate; electronic equivalents are not sufficiently secure; technology and/or switch to electronic environment is too costly.

Analysing the spotted factors, we note that we have two different types of obstacles. The first type includes legal issues and the second, technology issues which generate a chain of more obstacles [4] [5]. 


\subsection{Chartering}

The Charter is the basic contract of carriage. The terms of the Charter are determined by the obligations and rights of the parties and the chartering agreement is considered valid in any way and formulated to deal with all the issues that may arise as much as possible. For example, English law agreement has: Expressed terms, implied terms, representations, conditions, warranties and innominate terms. Different forms of brokering agreements are distinguished like standard Charter, agreed charter parties, adopted charter parties, recommended charter parties. The approved charter parties, depending on Chartering Type are: Voyage Charter, Time Charter and Bare boat Charter.

\subsection{Port Clearance}

Ports play a significant role in Maritime Industry, as freight must be loaded or departed on port stations and automation plays a key aspect to provide quick and efficient service. All vessels are obliged to obtain a Port Clearance Certificate (PCC) before departing or arriving at a specific port. The departure declaration, together with the relevant documents, must be made to the Maritime and Port Authority (MPA) to obtain the PCC. It is obvious that to obtain the port clearance certificates for a specific journey, multiple entities (port authorities and vessel owners/companies) are involved. Performing this process in a paper-based manner is inefficient (time and resource consuming).

\subsection{Blockchain and DLT Technologies}

Blockchain technology is indisputably at its hype. Blockchain is a technology that implies that 1) several nodes form a "blockchain network", 2) all these nodes keep a replica of a database, 3) the database is constructed in the form of chains of blocks where each block consists of multiple "transactions" and each block "points" of the older one in the chain with the pointer being calculated as a hash function of the data included in the block. To motivate the nodes perform the calculations, specific rewards are granted to the nodes/miners and the nodes implement a specific consensus mechanism to agree on the next block to be inserted in the chain.

The major benefits stemming from these basic principles are:

- The system is immune to single node attacks. If one of them is attacked, the network remains active, because the information is kept in multiple nodes;

- Immutable information-information integrity: nobody can alter a piece of information already stored in the blockchain, as this is protected by the hash which acts as a pointer to the block; changing the information in a block would require the alteration of all blocks from the altered one onwards from all nodes, which is practically impossible;

- Distributed operation of the information maintenance solution which implies equivalent distribution of the operational and capital expenditure costs.

The popularity of the blockchain technology has led to articles proposing its 
adoption in almost all sectors including private, public, energy, financial, record keeping, and identity management among others. However, blockchain is not a panacea and has to be carefully applied to provide solutions where its benefits justify its cost which is mainly due to the computational intensity.

When trying to design a blockchain-based solution, different design alternatives exist and the solutions architects have to make the relevant decisions:

- Private vs. public and permissioned vs. permission less: There is the option to create a public blockchain where anybody can join or a private blockchain where only nodes authorized by a certain authority can enter or a federated /consortium blockchain where a consortium agrees in the establishment of a network. The chosen type of the blockchain is also affecting the selection of the consensus mechanism as well as the transaction speed. Known Networks for those types of blockchain are: Ethereum (Public), Hyperledger Fabric (Private), Libra (Consortium).

- The structure of the information to be kept in the blockchain is also a design consideration. The "transaction" originally kept in the blockchain can be re-structured to accommodate other information or even to store pointers to files storage systems like IPFS (interplanetary file system) which is more likely to be the case in the maritime industry as well.

- Structure of the "database": while in blockchain, the information is stored in chains of blocks, there are more than ten platforms that implement other information structures. Other platform organizes the information in "blocks" of just one transaction or organizes the blocks in Directed Acyclic Graphs (and not chains). All these approaches (including blockchain) fall under the umbrella of Distributed Ledger Technologies. Despite the fact the blockchain is a sub-category of DLTs, the technology as a whole is widely known as blockchain.

- Definition of the architecture of the solution: i.e. definition of where the mining nodes are deployed, who owns them, where the applications to access the network are running and others. Apart from the positioning and ownership of the nodes, their different parameters have to be defined (such as consensus algorithms, platform specific parameters like channel organization in Hyperledger Fabric, etc.).

It is worth clarifying that in the sequel we refer to "platforms" as approach and open source code that could be used to develop a specific application/solution while "solution" is the software that a company with install and deploy in and for a shipping company, i.e. it is tailored to the specific use.

\section{Stage Two}

\section{Technical Aspects}

A first assessment of the presented solutions is included in Table 1 where the type of each solution and its main advantages and disadvantages are listed. It is clear that any solution needs to deploy a private or permissioned platform so 
Table 1. Blockchain-based e-BOL platforms and solutions.

\begin{tabular}{|c|c|c|c|}
\hline & Type & Advantages & Disadvantages \\
\hline CARGOX & $\begin{array}{l}\text { Public (restricted) } \\
\text { Ethereum-based } \\
\text { Blockchain }\end{array}$ & $\begin{array}{l}\text { Well Known blockchain House of Landing } \\
\text { Transactions are viewable to entire network } \\
\text { Helped blockchain to be acceptable in Shipping } \\
\text { Industry }\end{array}$ & $\begin{array}{l}\text { Does not support negotiable BOL } \\
\text { Not approved by P\&I clubs } \\
\text { High Value of tokens make transaction } \\
\text { unacceptable }\end{array}$ \\
\hline EssDocs-Voltron & $\begin{array}{l}\text { Permissioned } \\
\text { Based on Corda }\end{array}$ & $\begin{array}{l}\text { Cross-platform connectivity } \\
\text { Use R3 Corda Ricardian Contract }\end{array}$ & $\begin{array}{l}\text { Beta mode } \\
\text { Finance based model } \\
\text { Banks have access to all companies data } \\
\text { Cannot use token }\end{array}$ \\
\hline Tradelens & $\begin{array}{l}\text { Private (based on } \\
\text { Hyperledger Fabric) }\end{array}$ & $\begin{array}{l}\text { Generic platform for supply chain solutions } \\
\text { Promoted by IBM and Maersk }\end{array}$ & Doesn't provide maritime specific operations. \\
\hline e-title & $\begin{array}{l}\text { Peer } 2 \text { peer } \\
\text { Hybrid platform }\end{array}$ & $\begin{array}{l}\text { Accept any format of Document (PDF, IMAGE, } \\
\text { XML, EDI) }\end{array}$ & $\begin{array}{l}\text { Need of Paper Based bill of landing to convert it in } \\
\text { electronic Bill of Landing }\end{array}$ \\
\hline Edox Online & Web based blockchain & P\&I Clubs accepted & Lack of privacy \\
\hline Bolero & Cloud Based & $\begin{array}{l}\text { Scan paper documents } \\
\text { Manage Huge load of Documents }\end{array}$ & $\begin{array}{l}\text { Contractual provisions binding only the } \\
\text { contracting parties and cannot provide obligations } \\
\text { to third parties Centralized }\end{array}$ \\
\hline
\end{tabular}

that access to the information is fully controlled. From the access control perspective, Hyperledger Fabric based solution are advantageous because it is a private network build with inter-enterprise exchanges in mind. For this purpose, it supports the notion of "channels" where nodes communicated in the same "channel" essentially form a blockchain network. This way deploying HLF based solutions, multiple blockchain networks can run in parallel. This capability gives a purely operational form to the network that makes it more appealing to shipping organizations. For example, the different channels could be exploited to segregate groups of shipping organizations. On the other hand, Corda is more tailored to financial processes which are indispensable of any shipping operation.

As the need to register and maintain continuously growing amounts of information is evident, scalability play a crucial role. Scalability refers to the capacity of the solution to register and manage larger amounts of information (at adequate speed to avoid the degradation of the user experience) and unfortunately scalability is an inherent drawback of blockchain approaches. Additionally, today the trend is to register continuously increasing amounts of information for all goods in an attempt to offer enhanced security and added value services to the end users. Across all supply chains, actors seek to provide evidence to end users that the goods are appropriately handled and safe to use. This is nowadays feasible through the integration of sensor systems which are capable of collecting information across the journey of the goods installed in all places where the goods are placed. The need for handling continuously increasing amounts of information due to 1) the ordinary evolution and 2) the integration of additional information sources render scalability of paramount importance. Turning our attention to the scalability features of the existing solutions, scalability is not among the advantages of Ethereum. Hyperledger Fabric exhibits better scalabili- 
ty than Ethereum as it can organise the blockchain network in channels which could be seen as independent networks. Currently, it is DLTs that come at a rescue and exhibit better scalability features. For example, directed acyclic graph approaches come with higher scalability potential which of course depends on the way they are structured, and they operate [6].

\section{Stage Three}

\subsection{Research Methodology}

In order to measure the willingness of the Hellenic shipping industry to adopt and use blockchain applications in the near future, we conducted a quantitative survey.

Drawing on the literature on UTAUT and its modifications, blockchain, maritime industry and the network theory, the model of Figure 1 is presented to understand the willingness of blockchain adoption in the shipping industry field.

\subsection{Research Model}

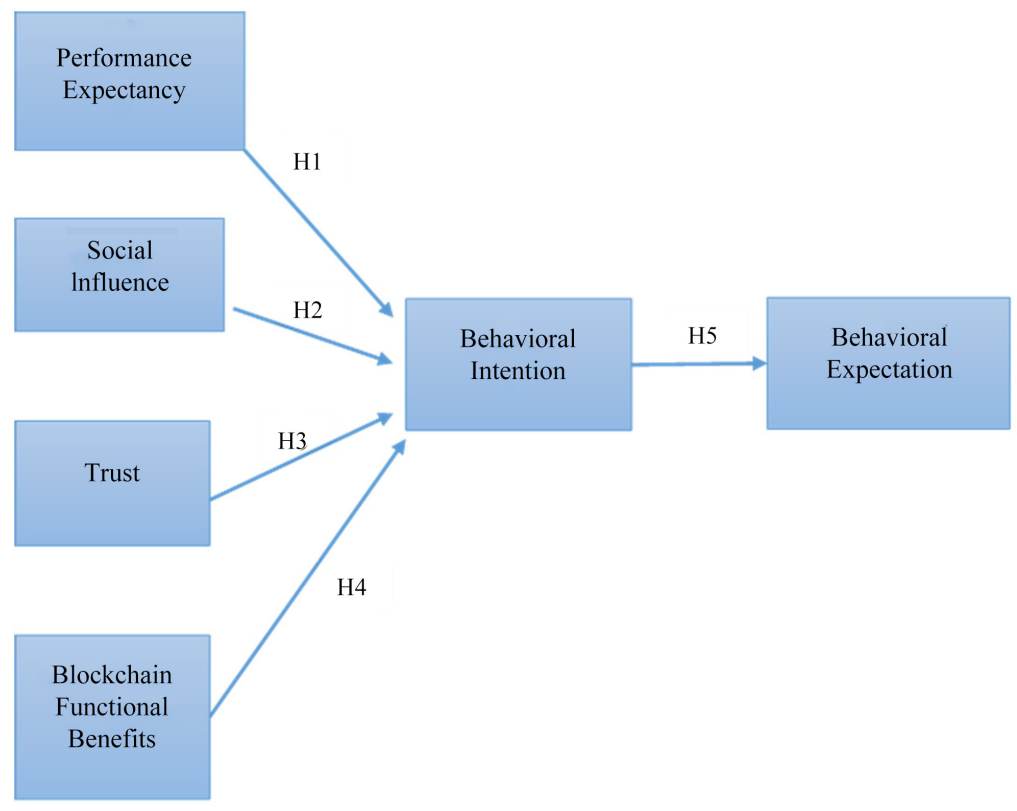

Figure 1. Proposed research model.

\subsection{Development of Hypotheses}

In this subsection, the selected constructs will be analyzed and the proposed hypotheses will be presented.

H1. Performance expectancy positively affects the behavioral intention to adopt blockchain.

H2. Social influence positively affects the behavioral intention to adopt blockchain.

H3. Trust between Maritime's industry stakeholders positively affects behavioral intention to adopt blockchain. 
H4. Blockchain Functional benefits positively affect behavioral intention for blockchain adoption.

H5. Behavioral intention positively affects behavioral expectation for blockchain adoption.

\subsection{Questionnaire}

An English questionnaire was created and reviewed for content validity by a group of university staff. The questionnaire contained a total of 30 questions (7 for constructing the demographic profile of the responders and 23 for measuring the selected constructs). All constructs were measured by a 7-point Likert scale (strongly disagree - strongly agree).

\subsection{Sampling Design and Data Collection}

The questionnaire was distributed to a sample of 378 people. At the end of the survey, 63 answered questionnaires were collected, but only 57 were considered to have been appropriately filled out and therefore suitable for supplementary analysis (response rate of $15.07 \%$ ).

\subsection{Data Analysis}

The data analysis has been conducted with the use of IBM SPSS Statistics v.21 software, in order to analyze the proposed model. The results are presented below, together with the measurement model.

\subsection{Willingness of the Hellenic Shipping Industry to Adopt Blockchain}

Behavioral Expectation $(\mathrm{BEXP})$ has a Mean $=4.2807$ which is greater than 3.5 Median $=4.3333$ and Skewness $=-0.500$. These values are clearly verified that the Hellenic shipping industry has the intention to adopt blockchain technology.

\subsection{Measurement Model}

The items for BFB, SINF, PEXP, and BEXP had a Cronbach's alpha coefficient of $0.90,0.90,0.91$, and 0.92 respectively, and indicating excellent reliability. The items for BTR and BINT had a Cronbach's alpha coefficient of 0.80 and 0.88 respectively, indicating good reliability.

A Spearman correlation analysis was conducted between PEXP, BTRU, SINF, BFB and BINT and between BINT and BEXP (Table 2).

\subsection{Linear Regression Analysis}

The results of the linear regression model were significant, $F(5,51)=5.26, \mathrm{p}<$ $0.001, \mathrm{R} 2=0.34$, indicating that approximately $34 \%$ of the variance in BEXP is explainable by BFB, BTR, PEXP, BINT, and SINF. BFB did not significantly predict $\mathrm{BEXP}, \mathrm{B}=-0.24$, $\mathrm{t}(51)=-1.03, \mathrm{p}=0.310$. Based on this sample, a one-unit increase in BFB does not have a significant effect on BEXP. BTR significantly 
predicted BEXP, $\mathrm{B}=-0.63, \mathrm{t}(51)=-2.39, \mathrm{p}=0.020$. This indicates that on average, a one-unit increase of BTR will decrease the value of BEXP by 0.63 units. PEXP did not significantly predict BEXP, $B=0.51, \mathrm{t}(51)=1.82, \mathrm{p}=0.075$. Based on this sample, a one-unit increase in PEXP does not have a significant effect on BEXP. BINT significantly predicted BEXP, $\mathrm{B}=0.37, \mathrm{t}(51)=2.35, \mathrm{p}=0.023$. This indicates that on average, a one-unit increase of BINT will increase the value of BEXP by 0.37 units. SINF did not significantly predict BEXP, B $=0.20$, t $(51)=$ $0.88, \mathrm{p}=0.382$. Based on this sample, a one-unit increase in SINF does not have a significant effect on BEXP. Table 3 summarizes the results of the regression model.

\section{Conclusions}

The First Stage of this thesis recognized the shipping industry sectors which can be benefited from the blockchain implementation. Among them, Bill of Lading seems to be the most difficult case, but also the most promising. By adopting a blockchain-based platform for BoLs, the shipping industry will fill a giant gap between todays' paper-based procedures and the future digitalized ones. The chartering and brokering sectors, through the implementation of Smart and Ricardian Contracts, will gain a more efficient, transparent and cost-effective shape, saving valuable time and funds for their users. Finally, all the sectors which handle documents and crucial characteristics such as authenticity and uniqueness will play a decisive role, as the implementation of the blockchain will

Table 2. Spearman correlation results.

\begin{tabular}{cccccc}
\hline & Combination & $r_{\mathrm{s}}$ & Lower & Upper & $\mathrm{p}$ \\
\hline H1: & PEXP-BINT & 0.55 & 0.33 & 0.71 & $<0.001$ \\
H2: & SINF-BINT & 0.43 & 0.19 & 0.62 & $<0.001$ \\
H3: & BTR-BINT & 0.31 & 0.05 & 0.53 & 0.003 \\
H4: & BFB-BINT & 0.41 & 0.17 & 0.61 & 0.002 \\
H5: & BINT-BEXP & 0.50 & 0.27 & 0.67 & $<0.001$ \\
\hline
\end{tabular}

Table 3. Regression model.

\begin{tabular}{ccccccc}
\hline Variable & $B$ & $S E$ & CI & $\beta$ & $t$ & $\mathrm{p}$ \\
\hline (Intercept) & 3.87 & 1.24 & {$[1.38,6.37]$} & 0.00 & 3.11 & 0.003 \\
BFB & -0.24 & 0.24 & {$[-0.72,0.23]$} & -0.20 & -1.03 & 0.310 \\
BTR & -0.63 & 0.26 & {$[-1.16,-0.10]$} & -0.32 & -2.39 & 0.020 \\
PEXP & 0.51 & 0.28 & {$[-0.05,1.07]$} & 0.40 & 1.82 & 0.075 \\
BINT & 0.37 & 0.16 & {$[0.05,0.69]$} & 0.34 & 2.35 & 0.023 \\
SINF & 0.20 & 0.22 & {$[-0.25,0.65]$} & 0.16 & 0.88 & 0.382 \\
\hline
\end{tabular}

Note. $\mathrm{CI}$ is at the $95 \%$ confidence level. Results: $\mathrm{F}(5,51)=5.26, \mathrm{p}<0.001, \mathrm{R} 2=0.34$; Unstandardized Regression Equation: $\mathrm{BEXP}=3.87-0.24{ }^{\star} \mathrm{BFB}-0.63 * \mathrm{BTR}+0.51$ * $\mathrm{PEXP}+0.37$ * $\mathrm{BINT}+0.20$ * SINF . 
enable them to eliminate fraud and drastically reduce their operating costs. Also, they will be able to upgrade the cyber security through the hack-proof capabilities of a DLT-based application. At Stage Two, the demonstrated use cases of blockchain-based applications and platforms give us a representative example of the new age in shipping industry transactions. New applications constantly appear and new alliances between shipping and IT companies are created. This proves the willingness of the shipping industry to adopt blockchain, in a general digital transformation framework. On the other hand, the blockchain and the DLTs in general are still facing many challenges to overcome. Industry standards and operating regulations must be defined. For those reasons, governments and international regulators such as IMO must take the lead and steer the course of the digital evolution. Moreover, the Hellenic shipping industry participants need to be prepared for the new technology as it is coming and they need to be ready to be able to take advantage of this game-changing technology. Additionally, more steps have to be made on the technology development from the Hellenic Institutes and Universities and include this innovative technology in their curricular in order to prepare the students and man for the IT companies with the appropriate professionals.

The Hellenic government can be also benefited from this technological revolution. As mentioned in Chapter 3, a legislative framework is crucial for the appliance of blockchain technology. Greece, by applying the following steps, combined with the influence that the Hellenic shipping companies exerts on the global ocean transports, can become the new global "Shipping Center". Firstly, it has to apply a framework based on international legislation like the UNCITRAL Model Law on Electronic Transferable Records and enact more blockchain-friendly laws. Secondly, a specialized blockchain shipping court, properly staffed by judges specialized in maritime law and with the appropriate technological know-how, needs to be created. The same strategy had been applied by Great Britain, when it enforced the English Law, using its "shipping power" which it had during the 18th and 19th century in the maritime procedures and establishing London as the shipping center of the non-digital era [7] [8].

Finally, at the Third Stage of this thesis, some light was shed on blockchain adoption behavior by the Hellenic shipping industry, while taking into account the behavior of the adopters from the most influential sectors. By analyzing the collected data from the distributed questionnaire, a willing behavior to adopt blockchain from the Hellenic shipping has been proved. Also, the investigation of the constructs "Performance Expectancy", "Social Influence", "Trust" and "Functional Benefits" has a significant positive correlation with the intention of the Hellenic's shipping industry stakeholders to adopt and use this new technology.

\section{Acknowledgements}

All authors would like to thank the University of West Attica and specifically the Post Graduate Program of Studies (MSc) "New Technologies in Shipping and 
Transport", for the financial support provided to them to undertake this research project.

\section{Conflicts of Interest}

The authors declare no conflicts of interest regarding the publication of this paper.

\section{References}

[1] Gonzalez, S., Luis, P., Díaz-Gutiérrez, D., Leo, T.J. and Núñez, L. (2019) Toward Digitalization of Maritime Transport? Sensors, 19, 926. https://doi.org/10.3390/s19040926

[2] Herd, J. (2018) "Blocks of Lading" Distributed Ledger Technology and the Disruption of Sea Carriage Regulation. QUT Law Review, 18, 306-317. https://doi.org/10.5204/qutlr.v18i2.755

[3] Brunner, R. (2007) Electronic Transport Documents and Shipping Practice Not Yet a Married Couple. LL.M. Shipping Law.

[4] United Nations Conference on Trade and Development, the Use of Transport Documents in International Trade, UNCTAD (2003).

[5] https://cargox.io/CargoX-Business-Overview-Technology-Bluepaper.pdf

[6] Venkatesh, V., Morris, M.G., Davis, G.B. and Davis, F.D. (2003) User Acceptance of Information Technology: Toward a Unified View. MIS Quarterly, 27, 425-478. https://doi.org/10.2307/30036540

[7] Takahashi, K. (2019) Bahraini Legislation Based on the UNCITRAL MLETR. Blockchain, Cryptocurrency, Crypto-Asset and the Law. Retrieved 12 February.

[8] Liu, H. (2020) Blockchain and Bills of Lading: Legal Issues in Perspective. In: Mukherjee P., Mejia, Jr.M. and Xu, J., Eds., Maritime Law in Motion. WMU Studies in Maritime Affairs, Vol. 8, Springer, Cham.

https://doi.org/10.1007/978-3-030-31749-2_19 